\title{
Load- and Interference-Balance Hybrid Routing Protocol for Hybrid Wireless Mesh Network
}

DOI:

10.1109/WD.2019.8734257

Document Version

Accepted author manuscript

Link to publication record in Manchester Research Explorer

\section{Citation for published version (APA):}

Chai, Y., \& Zeng, X. J. (2019). Load- and Interference-Balance Hybrid Routing Protocol for Hybrid Wireless Mesh Network. In 2019 Wireless Days, WD 2019 [8734257] (IFIP Wireless Days; Vol. 2019-April). IEEE Computer Society . https://doi.org/10.1109/WD.2019.8734257

\section{Published in:}

2019 Wireless Days, WD 2019

\section{Citing this paper}

Please note that where the full-text provided on Manchester Research Explorer is the Author Accepted Manuscript or Proof version this may differ from the final Published version. If citing, it is advised that you check and use the publisher's definitive version.

\section{General rights}

Copyright and moral rights for the publications made accessible in the Research Explorer are retained by the authors and/or other copyright owners and it is a condition of accessing publications that users recognise and abide by the legal requirements associated with these rights.

\section{Takedown policy}

If you believe that this document breaches copyright please refer to the University of Manchester's Takedown Procedures [http://man.ac.uk/04Y6Bo] or contact uml.scholarlycommunications@manchester.ac.uk providing relevant details, so we can investigate your claim.

\section{OPEN ACCESS}




\title{
Load- and Interference-Balance Hybrid Routing Protocol for Hybrid Wireless Mesh Network
}

\author{
Yuan Chai and Xiao-Jun Zeng \\ School of Computer Science \\ University of Manchester \\ Manchester, United Kingdom \\ yuan.chai-2@postgrad.manchester.ac.uk,x.zeng@manchester.ac.uk
}

\begin{abstract}
Routing protocol design is very important in network design, because an effective routing protocol can greatly improve network performance. As heavy and aggregated load and interference will decrease the performance, to balance load and interference, an effective load- and interference-balance hybrid routing protocol (LIB-HRP) is proposed in this paper. Unlike existing hybrid routing protocols, LIB-HRP considers the load condition at interfering nodes, because the interfering node with heavy load will have much influence on the current node. The heavier load condition at interfering node can bring a longer duration of interference. Besides, as mesh clients have limited energy, energy condition is taken into account for mesh clients in the proposed approach. Simulation results show that LIB-HRP can obtain better performance in terms of average packet loss ratio, delay, network throughput and energy consumption.

Index Terms-hybrid routing protocol, hybrid wireless mesh network, load, interference, energy
\end{abstract}

\section{INTRODUCTION}

Hybrid wireless mesh network (WMN) is composed of static mesh routers and mobile mesh clients. The mesh routers compose infrastructure WMN and mesh clients constitute client WMN [1]. Fig. 1 shows the network model of hybrid WMN

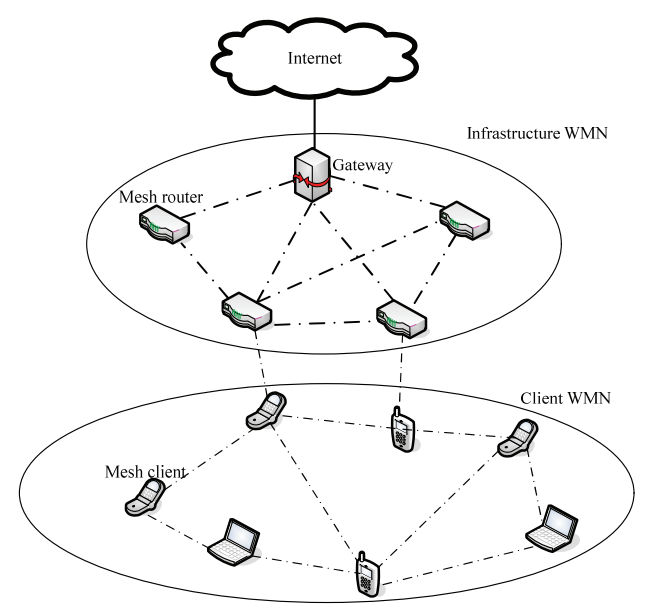

Fig. 1. Network model of hybrid WMN.

Mesh routers have multiple interfaces, and the interfaces of each mesh router can be connected with orthogonal wireless channels. Mesh clients have only one interface, and this interface needs to be bonded with a common channel used by mesh routers, which can guarantee the smooth communication between mesh routers and mesh clients.

An effective routing protocol can find routes with good performance from sources to destinations. Designing a good routing protocol can improve the whole network performance dramatically. Routing protocols can be categorized into proactive, reactive and hybrid routing protocols [2]. Proactive routing protocols work well among static mesh routers, whereas reactive routing protocols are suitable for mobile mesh clients. Thus, the hybrid routing protocols which is composed of both proactive and reactive routing protocols are very useful and can be adaptive for hybrid WMN, because hybrid WMN includes both static mesh routers and mobile mesh clients. However, the existing research of hybrid routing protocol is few, and the load- and interference-balance problem is not taken into consideration sufficiently.

To overcome the weakness of existing hybrid routing protocols, a load- and interference-balance hybrid routing protocol (LIB-HRP) is proposed in this paper, which can identify and avoid nodes and regions with high interference and load. Different from existing hybrid routing protocols, LIBHRP considers the load and interference condition. The load conditions at current node, neighboring nodes and interfering nodes are all taken into account. Besides the packets at current node, the packets waiting to be transmitted at neighboring and interfering nodes can also influence the network condition at the current node, because the packets at neighboring nodes have the probability to be transmitted to the current node, and the packets at interfering nodes will bring interference caused by the contention of accessing the wireless channel with the current node. Further, different features of mesh routers and mesh clients are also considered in LIB-HRP. Mesh clients have limited energy, and they cannot be used any more if they run out of energy. For this reason, for mesh clients, energy is also considered when selecting paths. The mesh clients with more remaining energy are preferred to be used. On the other hand, as mesh routers have no energy limitation, they are used to forward packets in priority. In this way, the energy will be saved, and energy consumption efficiency can be improved.

The structure of the remaining paper is: Section 2 introduces some related works. Section 3 proposes and explains LIB-HRP in detail. Simulation results are given in Section 4. Section 5 concludes the paper. 


\section{RELATED WORKS}

There is no much research about routing protocols for hybrid WMN currently. Most existing routing protocols for hybrid WMN are reactive routing protocols, because they can adapt to the high mobility of mesh clients. SafeMesh [3] considers the channel diversity and sets different weight values for mesh routers and clients respectively. AODV-DF [4] uses the flooding control method to reduce network overhead. FW-AODV [5] takes cost into account to design a new routing metric. EPTR [6] maximizes the network throughput by predicting the expected throughput which is influenced by interference.

However, only reactive routing protocols do not consider the feature of static mesh routers, and the delay caused by finding paths among mesh routers will occur. Although hybrid routing protocols can work well in hybrid WMN, the research about hybrid routing protocols is few. The limited available research results are HMesh [7] with proactive routing protocol OLSR [8] and reactive routing protocol AODV [9], and HDV [10] which is based on tree establishment. However, HMesh and HDV only use the hop count as the standard of selecting paths and neglect the network condition.

\section{LOAD- AND INTERFERENCE-BALANCE HYBRID ROUTING PROTOCOL}

To improve the existing hybrid routing protocols and balance the load and interference, LIB-HRP is proposed in this section. The load conditions of current node, neighboring nodes and interfering nodes are all considered. Further, for mesh clients, energy is also taken into account.

\section{A. Available Bandwidth}

Bandwidth is a very important factor to evaluate network condition. Large bandwidth can help nodes transmit packets fast. Bandwidth is influenced by interference. Both physical and logical interferences are considered in LIB-HRP. For the physical interference, $I R$ [11] is used to evaluate its amount. For the logical interference, the cross-layer method $C B T$ [12] is used to evaluate the busy condition of wireless channel. Then according to the physical and logical interferences, the available bandwidth of link $l$ (denoted as Band $d_{\text {available }}^{l}$ ) can be expressed as

$$
\text { Band }_{\text {available }}^{l}=B_{0} \cdot\left(1-C B T_{l}\right) \cdot I R_{l}
$$

where $B_{0}$ is the nominal bandwidth.

\section{B. Weight Values}

Weight values are used to evaluate the condition of mesh nodes. The nodes with less weight values mean that they have better performance. Based on the different features of mesh routers and mesh clients, the weight values of mesh routers and clients are set around 1 and 4 respectively [3]. Then the probabilities of mesh routers and mesh clients being used are about $80 \%$ and $20 \%$.
1) Mesh Routers: For mesh routers, both the load and interference conditions are taken into account. The queue length is used to evaluate the load condition. The queue length that the current mesh router $i$ can get from its neighbors (denoted as $Q L_{i}^{g e t}$ ) is

$$
Q L_{i}^{g e t}=\sum_{a \in N_{i}}\left(Q L_{a} \times p_{a_{-} i}\right)
$$

where $N_{i}$ is the neighbor set of mesh router $i$, which are the mesh nodes within the transmission range of mesh router $i$. $Q L_{a}$ is the queue length at the neighboring mesh node $a$, and $p_{a_{-} i}$ is the probability that the neighboring mesh node $a$ transmits packets to current mesh router $i$. For the same kind of mesh nodes, the probability of transmitting packets from the current node to the neighbors is assumed to be same.

In addition to the current packets at mesh router $i$ itself, mesh router $i$ also needs to empty the packets gotten from its neighbors. Then the time cost by emptying all these packets (denoted as $T_{i}$ ) is

$$
T_{i}=\frac{\left(Q L_{i}+Q L_{i}^{g e t}\right) \times \text { PacketSize }}{\text { Band }_{\text {available }}^{i}}
$$

where $Q L_{i}$ is the current queue length at mesh router $i$, and PacketSize is the size of each data packet. So $T_{i}$ is the ratio of all the number of bits at mesh router $i$ to the available bandwidth, which is the time of transmitting all the packets at mesh router $i$.

Further, the queue length at interfering nodes is also considered in LIB-HRP. The interfering node with the longer queue length has more influence on current mesh router $i$, because it may cause longer time of interference due to the contention of wireless channel. The influence of interfering nodes to current mesh router $i$ (denoted as $I_{i}$ ) can be expressed as

$$
I_{i}=\sum_{b \in \text { Inter }_{i}} \frac{Q L_{b} \times \text { PacketSize }}{\text { Band }_{\text {available }}^{b}}
$$

where Inter $_{i}$ is the set of interfering nodes of current mesh router $i$. Interfering nodes are the nodes which are sending the signal not being respected to be received by mesh router $i$. $Q L_{b}$ is the queue length at interfering node $b$.

According to the time cost by emptying packets and the influence of interfering nodes, the weight value of mesh router $i$ (denoted as $W e i g h t_{i}$ ) can be set as

$$
\begin{aligned}
& \text { Weight }{ }_{i}=T_{i}+I_{i}=\frac{\left(Q L_{i}+Q L_{i}^{\text {get }}\right) \times \text { PacketSize }}{\text { Band }}+ \\
& \sum_{b \in \text { Inter }_{i}} \frac{Q L_{b} \times \text { PacketSize }}{\text { Band available }}
\end{aligned}
$$

The mesh routers with less weight values will be selected, then the time cost by emptying queuing packets and waiting interfering nodes transmitting packets is reduced. So the area with heavy load and interference can be avoided.

2) Mesh Clients: For mesh clients, load and interference is also considered and balanced. In addition, as they have limited energy, the energy condition is considered at the same time. 
Similar to the mesh routers, the weight part of the load and interference for mesh client $j$ (denoted as $W_{j}$ ) is

$$
W_{j}=T_{j}+I_{j}=\frac{\left(Q L_{j}+Q L_{j}^{\text {get }}\right) \times \text { PacketSize }}{\sum_{d \in \text { Inter }_{j}} \frac{\text { Band }_{\text {avqilable }}^{j} \times \text { PacketSize }}{\text { Band available }}}+
$$

Then for the energy part, the remaining energy condition is considered. The residual energy ratio (denoted as $E_{j}$ ) is

$$
E_{j}=\frac{E_{\text {residual }}^{j}}{E_{\text {total }}^{j}}
$$

where $E_{\text {residual }}^{j}$ is the residual energy of mesh client $j$, and $E_{\text {total }}^{j}$ is the total energy of mesh client $j$ when fully charged.

Then the weight value of mesh client $j$ (denoted as $W_{\text {eight }}$ ) can be set as

$$
W e i g h t_{j}=W_{j}+E_{j}+4
$$

The mesh client with less weight value will be chosen to use, which means the mesh client with less load and interference, more residual energy will be used. The network performance can then be improved.

\section{Routing Metric}

The routing metric is the criterion of selecting paths. It is the sum of weight values of mesh nodes on one path (denoted as Metric), which can be expressed as

$$
\text { Metric }=\sum_{j \in \text { Client }} \text { Weight }_{j}+\sum_{i \in \text { Router }} \text { Weight }_{i}
$$

where Client is the set of mesh clients on the path, and Router is the set of mesh routers on the path. The route with least value of routing metric will be selected. As mesh routers have less weight values than mesh clients, they are selected in priority to save energy and make the chosen routes more stable. The mesh nodes and areas with less load and interference will be finally used to transmit packets. The load and interference can be balanced in this way.

\section{Simulation Evaluation}

To evaluate the performance of LIB-HRP, the simulation through NS3 [13] is implemented. Each simulation scenario is run 5 times.

\section{A. Simulation Parameters}

Static mesh routers are deployed into a grid, and mesh clients are deployed randomly. As mesh clients are mobile, they can move randomly. The number of data flows and the packet transmission rate is changed in the simulation. The detailed simulation parameters are given in Table I.

To evaluate the network performance accurately, some criteria are used.

- Average packet loss ratio: the ratio of the number of lost packets to the total transmitted packets.

- Average delay: the time cost by transmitting a packet from the source to the destination.
TABLE I

Simulation PARAMETERS

\begin{tabular}{|c|c|}
\hline Simulation Parameters & Values \\
\hline Simulation time & $100 \mathrm{~s}$ \\
\hline Traffic type & UDP \\
\hline Packet size & 1024 bytes \\
\hline Number of mesh routers & 25 \\
\hline Number of mesh clients & 50 \\
\hline Number of radio interfaces in each router & 3 \\
\hline Number of radio interfaces in each client & 1 \\
\hline Antenna & Omnidirectional \\
\hline
\end{tabular}

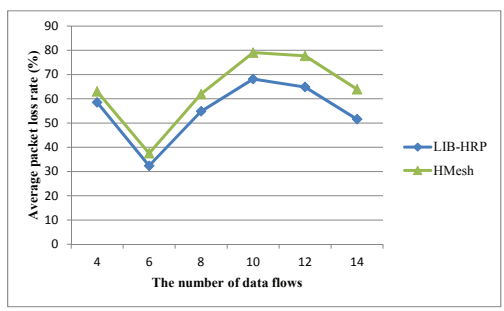

(a) Different number of data flows

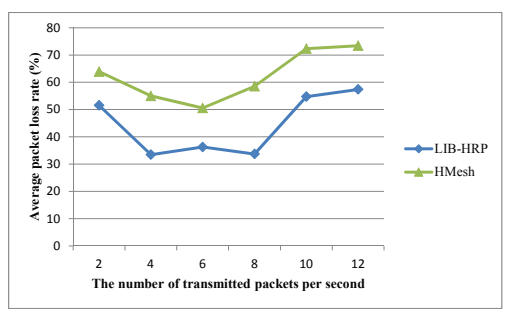

(b) Different number of transmitted packets per second

Fig. 2. Average packet loss ratio with

- Average network throughput: the amount of bits that can be received successfully per second.

- Average energy consumption of mesh clients: the energy of mesh clients that is consumed by transmitting each packet.

\section{B. Simulation Results}

With different number of flows and transmission rate, the simulation results are shown from Fig. 2 - Fig. 5.

From Fig. 2 - Fig. 5, we can see that LIB-HRP can get better network performance than HMesh. HMesh only selects the path with least hop count, and neglects all other network condition. Heavy load and interference will be caused when one common node is overused, which can decrease the network performance. Different from HMesh, LIB-HRP balances load and interference, and the load condition at current node, neighboring nodes and interfering nodes is all taken into consideration. Then the node and area with more load and interference can be avoided. In addition, LIB-HRP also considers the limited energy of mesh clients. Mesh clients with more residual energy and mesh routers are used in priority. Then the energy of mesh clients can be saved, and the energy consumption is balanced. Thus, LIB-HRP can achieve better performance. 


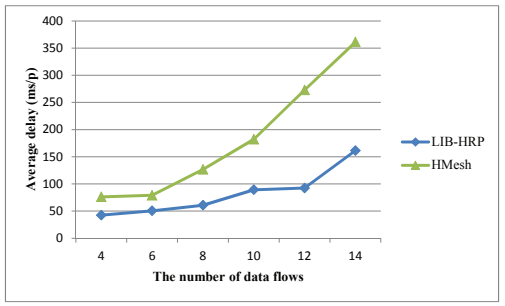

(a) Different number of data flows

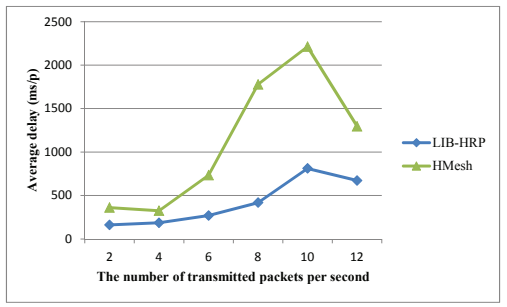

(b) Different number of transmitted packets per second

Fig. 3. Average delay with

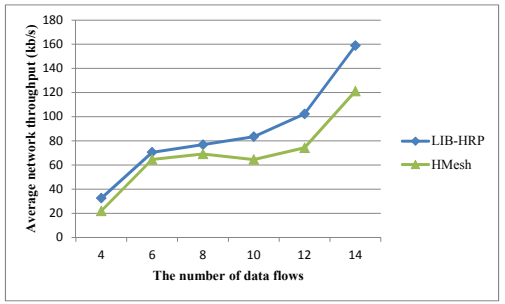

(a) Different number of data flows

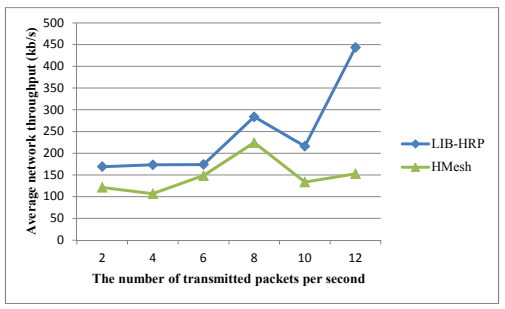

(b) Different number of transmitted packets per second

Fig. 4. Average network throughput with

\section{CONCLUSIONS}

Hybrid routing protocol can work well in hybrid WMN. However, existing hybrid routing protocols neglect load condition at interfering nodes. The interfering nodes with heavier load have stronger influence on the current node because they will cause longer duration of interference. LIB-HRP proposed in this paper covers the weakness, and balances load and interference. The regional load and interference is considered, and the node and area with less load and interference will be selected to forward packets. Besides, energy is also considered in LIB-HRP. The mesh client with less residual energy will be avoided to be used. The simulation results through NS3 show that LIB-HRP can achieve better network performance

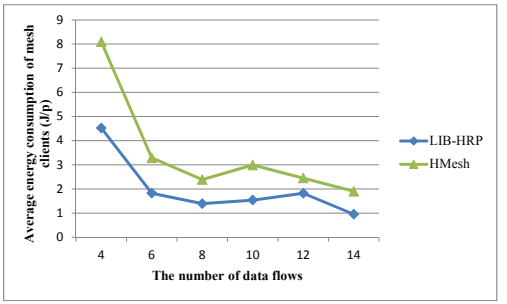

(a) Different number of data flows

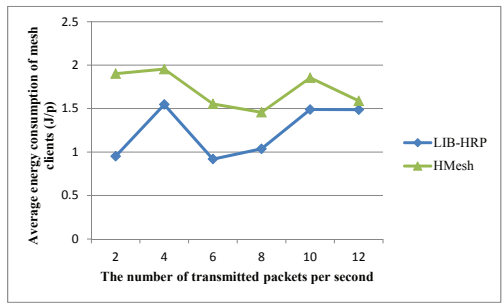

(b) Different number of transmitted packets per second

Fig. 5. Average energy consumption of mesh clients with

in terms of average packet loss ratio, average delay, average network throughput and energy consumption of mesh clients.

\section{REFERENCES}

[1] D. Benyamina, A. Hafid, and M. Gendreau, Wireless mesh networks design-A survey, IEEE Communications Surveys \& Tutorials, vol. 14, no. 2, pp. 299-310, 2012.

[2] A. Al-Saadi, R. Setchi, Y. Hicks, and S. M. Allen, Routing protocol for heterogeneous wireless mesh networks, IEEE Trans. on Vehicular Technology, vol. 65, no. 12, pp. 9773-9786, 2016.

[3] A. A. Pirzada, M. Portmann, R. Wishart, and J. Indulska, SafeMesh: A wireless mesh network routing protocol for incident area communications, Pervasive and Mobile Computing, vol. 5, no. 2, pp. 201-221, 2009.

[4] D. W. Kum, A. N. Le, Y. Z. Cho, C. K. Toh, and I. S. Lee, An efficient on-demand routing approach with directional flooding for wireless mesh networks, Journal of Communications and Networks, vol. 12, no. 1, pp. 67-73, 2010.

[5] A. Singh, S. S. Walia, and S. Kumar, FW-AODV: An Optimized AODV Routing Protocol for Wireless Mesh Networks, International Journal of Advanced Research in Computer Science, vol. 8, no. 3, pp. 1131-1135, 2017.

[6] X. Deng, L. He, Q. Liu, X. Li, L. Cai, and Z. Chen, EPTR: expected path throughput based routing protocol for wireless mesh network, Wireless Networks, vol. 22, no. 3, pp. 839-854, 2016.

[7] L. Zhao, Z. Yu, J. Niu, H. Zhang, and W. Ding, A hybrid routing protocol for hierarchy wireless mesh networks, In 6th international conference on wireless communications networking and mobile computing (WiCOM), pp. 1-4, 2010.

[8] T. Clausen, and P. Jacquet, Optimized link state routing protocol (OLSR), 2003.

[9] C. Perkins, E. Belding-Royer, and S. Das, Ad hoc on-demand distance vector (AODV) routing, 2003.

[10] A. N. Le, D. W. Kum, and Y. Z. Cho, An efficient hybrid routing approach for hybrid wireless mesh networks, Advances in Information Security and Assurance, vol. 5576, pp. 532-542, 2009.

[11] V. C. Borges, D. Vieira, M. Curado, and E. Monteiro, Routing metric for interference and channel diversity in multi-radio wireless mesh network, In 8th International Conference on Ad-Hoc Networks and Wireless, pp. 55-68, 2009.

[12] V. C. Borges, M. Curado, and E. Monteiro, Cross-layer routing metrics for mesh networks: Current status and research directions, Computer Communications, vol. 34, no. 6, pp. 681-703, 2011.

[13] ns-3. https://www.nsnam.org/. Accessed November 5, 2018. 